\title{
Hypoventilation improves oxygenation after bidirectional superior cavopulmonary connection
}

Scott M. Bradley, MD

Janet M. Simsic, $M D^{b}$

Denise M. Mulvihill, MD

From the Divisions of Cardiothoracic Surgery, ${ }^{a}$ Pediatric Cardiology, ${ }^{\mathrm{b}}$ and Radiology, ${ }^{c}$ Medical University of South Carolina, Charleston, SC

Received for publication Aug 27, 2002; revisions requested Oct 25, 2002; revisions received Nov 27, 2002; accepted for publication Dec 9, 2002.

Address for reprints: Scott M. Bradley, MD, Division of Cardiothoracic Surgery, Medical University of South Carolina, 96 Jonathan Lucas St., Charleston, SC 29425 (E-mail: bradlesm@musc.edu).

J Thorac Cardiovasc Surg 2003;126:1033-9

Copyright (๑) 2003 by The American Association for Thoracic Surgery

$0022-5223 / 2003 \$ 30.00+0$

doi:10.1016/S0022-5223(03)00203-4
Objective: Bidirectional superior cavopulmonary connection may be complicated by systemic hypoxemia. Previous work has shown that hyperventilation worsens systemic oxygenation in patients after bidirectional superior cavopulmonary connection. The likely mechanism is that hyperventilation-induced hypocarbia decreases cerebral, superior vena caval, and pulmonary blood flow. The aim of the current study was to determine whether the converse approach, hypoventilation, improves oxygenation after bidirectional superior cavopulmonary connection.

Methods: This is a prospective, patient-controlled study of 15 patients (median age 8.0 months, range 4.7-15.5) who underwent bidirectional superior cavopulmonary connection. Patients were studied in the intensive care unit, within 8 hours of surgery, while sedated, paralyzed, and mechanically ventilated. To avoid acidosis during hypoventilation, sodium bicarbonate was administered before hypoventilation. Cerebral blood flow velocity was measured by transcranial Doppler sonography of the middle cerebral artery.

Results: Hypoventilation following administration of sodium bicarbonate $(\mathrm{pH}-$ buffered hypoventilation) produced hypercarbia (mean $\mathrm{PCO}_{2}=58 \mathrm{~mm} \mathrm{Hg}$ versus 42 $\mathrm{mm} \mathrm{Hg}$ at baseline). During hypoventilation, there were significant increases in both mean arterial $\mathrm{PO}_{2}$ (from $50 \mathrm{~mm} \mathrm{Hg}$ at baseline to $61 \mathrm{~mm} \mathrm{Hg} ; P<.05$ ) and mean systemic oxygen saturation (from $86 \%$ at baseline to $90 \% ; P<.05$ ). These increases occurred despite accompanying, small increases in pulmonary artery pressure and transpulmonary gradient. Hypoventilation also produced an increase in mean cerebral blood flow velocity (from $37 \mathrm{~cm} / \mathrm{s}$ at baseline to $55 \mathrm{~cm} / \mathrm{s} ; P<.05$ ) and a decrease in the arteriovenous oxygen saturation difference across the upper body (from $33 \%$ at baseline to $23 \% ; P<.05$ ), consistent with increased cerebral blood flow.

Conclusions: This study demonstrates that hypoventilation improves systemic oxygenation in patients after bidirectional superior cavopulmonary connection. The likely mechanism for this effect is that hypoventilation-induced hypercarbia decreases cerebral vascular resistance, thus increasing cerebral, superior vena caval, and pulmonary blood flow. Hypoventilation may be a useful clinical strategy in patients who are hypoxemic in the early postoperative period after bidirectional superior cavopulmonary connection.

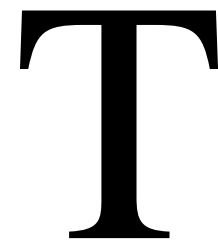

he bidirectional superior cavopulmonary connection (BSCC) is a commonly performed operation in patients with functional single ventricles. BSCC is typically used as an intermediate stage before a subsequent Fontan procedure. ${ }^{1,2}$ BSCC provides pulmonary blood flow by connecting the superior vena cava to the undivided pulmonary arteries. This connection places the cerebral and pulmonary vascular beds in series. In patients with a BSCC, changes in cerebral blood flow would therefore be expected to alter pulmonary blood flow. 
BSCC may be complicated by systemic hypoxemia. In the first 48 hours after this operation, some patients have low systemic oxygen saturations, which typically improve by the time of hospital discharge. ${ }^{3-5}$ Young age has been found to be a risk factor for such early postoperative hypoxemia. ${ }^{3,6}$ Occasionally, patients have oxygen saturations low enough that they require augmentation of their pulmonary blood flow by addition of a systemic-to-pulmonary artery shunt. ${ }^{1,2,4}$ Postoperative hypoxemia can also contribute to patient mortality after BSCC. ${ }^{3,4,7}$

In the setting of single ventricle physiology, elevated pulmonary vascular resistance can limit pulmonary blood flow, with resulting hypoxemia. ${ }^{8}$ Hyperventilation decreases pulmonary resistance in infants after cardiac surgery ${ }^{8}$ and may be routinely used after BSCC. ${ }^{6}$ However, previous work by our group has shown that hyperventilation actually impairs, rather than improves, systemic oxygenation in patients after BSCC. ${ }^{9}$ The probable explanation for this effect is that hyperventilation produces hypocarbia, which increases cerebral vascular resistance and decreases cerebral blood flow. ${ }^{10,11}$ After BSCC, decreased cerebral flow will result in less flow through the superior vena cava, less pulmonary blood flow, and lower systemic oxygen levels. In support of this explanation, our previous study also found that cerebral blood flow velocity decreased during hyperventilation. ${ }^{9}$ The aim of the current study was to determine whether the converse approach, hypoventilation, improves systemic oxygenation after BSCC.

\section{Methods \\ Patients}

This study was approved by the Institutional Review Board of the Medical University of South Carolina; informed consent was obtained for all patients. Fifteen patients undergoing BSCC were prospectively enrolled. Their median age was 8.0 months (range, 4.7-15.5 months) and median weight was $7.1 \mathrm{~kg}$ (range, 5.0-9.4 $\mathrm{kg}$ ). Eight were boys and 7 were girls. Diagnoses were: hypoplastic left heart syndrome ( 7 patients), tricuspid atresia (3 patients), unbalanced atrioventricular septal defect (2 patients), pulmonary atresia with intact septum (1 patient), double outlet right ventricle with mitral stenosis (1 patient), and double-inlet left ventricle (1 patient). Previous operations were: Norwood procedures (10 patients) and modified Blalock-Taussig shunts (3 patients); 2 patients were previously unoperated. Preoperative catheterization showed pulmonary venous wedge pressure (reflecting mean pulmonary artery pressure $)=13 \pm 2 \mathrm{~mm} \mathrm{Hg}$ (6 patients) and pulmonary vascular resistance $=2.1 \pm 0.9$ units $\cdot \mathrm{m}^{2}$ (7 patients $)$.

\section{Surgical Techniques}

BSCC consisted of a hemi-Fontan procedure (9 patients $)^{3,12-14}$ or a bidirectional Glenn shunt (6 patients). ${ }^{1-3}$ All systemic-to-pulmonary artery shunts and native pulmonary outflow tracts were divided at the time of BSCC. Ten patients underwent concomitant procedures: pulmonary artery patch augmentation (4 patients), division of main pulmonary artery ( 2 patients), left bidirectional
Glenn shunt (2 patients), atrial septectomy (1 patient), patch closure of left atrioventricular valve (1 patient), tricuspid valvuloplasty (1 patient), resection of subaortic stenosis (1 patient), and intraoperative balloon dilation of aortic coarctation (1 patient).

All operations were performed through a median sternotomy and utilized cardiopulmonary bypass (mean $172 \pm 37$ minutes). Aortic crossclamping and myocardial cardioplegic arrest were utilized in 11 patients (mean $51 \pm 11$ minutes). Deep hypothermia and circulatory arrest were utilized in 8 patients (mean $26 \pm 10$ minutes).

\section{Study Protocol}

Patients were studied in the intensive care unit, within 8 hours of surgery. During the study, patients were sedated (fentanyl at 20 $\mu \mathrm{g} / \mathrm{kg} / \mathrm{h}$ infusion) and paralyzed (vecuronium at $0.1 \mathrm{mg} / \mathrm{kg} / \mathrm{h}$ infusion). All patients received either amrinone at $10 \mu \mathrm{g} / \mathrm{kg} / \mathrm{min}(10$ patients) or milrinone at 0.5 to $0.75 \mu \mathrm{g} / \mathrm{kg} / \mathrm{min}$ ( 5 patients). Ten patients also received dopamine at 2 to $10 \mu \mathrm{g} / \mathrm{kg} / \mathrm{min}$. All infusions were maintained at constant rates, no patient had significant bleeding, and no blood transfusions were given during the study. Patients were either in sinus rhythm or atrially paced at a constant rate. Patients were mechanically ventilated with a Servo 300 ventilator (Siemens-Elema AB, Solna, Sweden) in pressure-regulated volume control mode. $\mathrm{FIO}_{2}$ was set at 1.0, peak end-expiratory pressure (PEEP) at $0 \mathrm{~cm} \mathrm{H}_{2} \mathrm{O}$, and tidal volume at 14 to 18 $\mathrm{mL} / \mathrm{kg}$; ventilator rate was adjusted to achieve a normal $\mathrm{pH}$ and $\mathrm{PCO}_{2}$ at baseline. Patients were maintained at normothermia $\left(37^{\circ} \mathrm{C}\right)$ throughout the study.

Each patient was studied at 3 consecutive time points: (1) baseline, during normal ventilation; (2) after administration of sodium bicarbonate (4 mEq/kg); and (3) during hypoventilation. Hypoventilation was achieved by decreasing the ventilator rate, while keeping constant all other ventilator settings (tidal volume, inspiratory time, $\mathrm{FIO}_{2}$, PEEP). Blood gas measurements and hemodynamic and transcranial Doppler determinations were obtained after at least a 15-minute stabilization period at each time point of the protocol.

Arterial blood gases were determined from samples drawn from radial or femoral arterial catheters. Systemic oxygen saturation was measured by pulse oximetry (Nellcor) and verified by oximetry (Radiometer Medical A/S, Copenhagen). Atrial and pulmonary artery pressures were measured via transthoracic lines placed in the operating room. Transpulmonary gradient was derived as pulmonary artery minus atrial pressure. Pulmonary artery oxygen saturation was measured from samples drawn from pulmonary artery lines. Cerebral blood flow velocity was measured by transcranial Doppler sonography of the middle cerebral artery (12 patients) or the anterior cerebral artery (2 patients). An Acuson Sequoia ultrasound device (Siemens) was placed over the temporal window and adjusted to obtain a maximal signal from the M1 segment of the middle cerebral artery. Mean flow velocity was determined by the Sequoia technical package.

\section{Statistics}

Results are shown as mean \pm SEM. Comparison of the 3 times of the study protocol was by repeated measures ANOVA. Multiple comparison testing was by Student-Newman-Keuls tests. Statistical significance was defined as $P<.05$. 
TABLE 1. Acid-base status; ventilation

\begin{tabular}{lccc}
\hline & $\begin{array}{c}\text { Time 2, } \\
\text { baseline }\end{array}$ & $\begin{array}{c}\text { metabolic } \\
\text { alkalosis }\end{array}$ & $\begin{array}{c}\text { Time 3, } \\
\text { hypoventilation }\end{array}$ \\
\hline $\mathrm{pH}$ & $7.39 \pm 0.01$ & $7.47 \pm 0.01^{*}$ & $7.36 \pm 0.01 \dagger$ \\
$\mathrm{PCO}_{2}(\mathrm{~mm} \mathrm{Hg})$ & $42 \pm 2$ & $45 \pm 2^{*}$ & $58 \pm 2 \dagger$ \\
Bicarbonate (mmol/L) & $25 \pm 1$ & $32 \pm 1^{*}$ & $31 \pm 1^{*}$ \\
Sodium (mEq/L) & $146 \pm 1$ & $151 \pm 1^{*}$ & $151 \pm 1^{*}$ \\
Rate (breaths/min) & $21 \pm 1$ & $21 \pm 1$ & $14 \pm 1 \dagger$ \\
Tidal volume (mL) & $108 \pm 5$ & $108 \pm 5$ & $108 \pm 5$ \\
Airway pressure (cm $\left.\mathrm{H}_{2} \mathrm{O}\right)$ & & & \\
$\quad$ Peak & $24 \pm 1$ & $25 \pm 1$ & $25 \pm 1$ \\
$\quad$ Mean & $6.0 \pm 0.4$ & $5.9 \pm 0.4$ & $3.9 \pm 0.3 \dagger$ \\
\hline
\end{tabular}

${ }^{*} P<.05$ versus baseline (Time 1 ; ANOVA).

$\dagger P<.05$ versus baseline and metabolic alkalosis (Times 1 and 2; ANOVA).

\section{Results}

Acid-Base Status; Ventilation

Treatment with sodium bicarbonate produced metabolic alkalosis; subsequent hypoventilation produced hypercarbia. At baseline, mean bicarbonate level was $25 \pm 1 \mathrm{mmol} / \mathrm{L}$, pH was $7.39 \pm 0.01$, and $\mathrm{PCO}_{2} 42 \pm 2 \mathrm{~mm} \mathrm{Hg}$ (Table 1). After administration of bicarbonate (Time 2), bicarbonate level rose to $32 \pm 1 \mathrm{mmol} / \mathrm{L}$ and $\mathrm{pH}$ to $7.47 \pm 0.01$, while $\mathrm{PCO}_{2}$ showed a numerically small change from baseline (Table 1). Hypoventilation was then achieved by decreasing the ventilator rate from a mean of 21 to 14 breaths per minute, while keeping the tidal volume constant (Table 1). During hypoventilation (Time 3), bicarbonate remained 31 $\pm 1 \mathrm{mmol} / \mathrm{L} ; \mathrm{PCO}_{2}$ rose to $58 \pm 2 \mathrm{~mm} \mathrm{Hg}$, and $\mathrm{pH}$ fell to $7.36 \pm 0.01$ (Table 1). During hypoventilation, peak airway pressures did not change, while mean airway pressures decreased (Table 1).

\section{Oxygenation}

Hypoventilation resulted in significant increases in arterial $\mathrm{PO}_{2}$ and systemic oxygen saturation. At baseline, mean arterial $\mathrm{PO}_{2}$ was $50 \pm 2 \mathrm{~mm} \mathrm{Hg}$, and systemic oxygen saturation was $86 \pm 2 \%$ (Figure 1). After administration of bicarbonate (Time 2), neither $\mathrm{Po}_{2}$ nor oxygen saturation changed significantly (Figure 1). During hypoventilation (Time 3), mean $\mathrm{Po}_{2}$ increased to $61 \pm 2 \mathrm{~mm} \mathrm{Hg}$, and mean systemic oxygen saturation to $90 \% \pm 1 \%$ (Figure 1).

\section{Hemodynamics}

Hypoventilation resulted in small but significant increases in pulmonary artery pressure and transpulmonary gradient (Figure 2). After administration of bicarbonate, atrial pressure, pulmonary artery pressure, and mean blood pressure increased slightly, although none of these changes was significant (Figure 2, Table 2). During hypoventilation, mean pulmonary artery pressure increased (from $14 \pm 1$ to $15 \pm 1 \mathrm{~mm} \mathrm{Hg} ; P<.05$ ), while atrial pressure did not
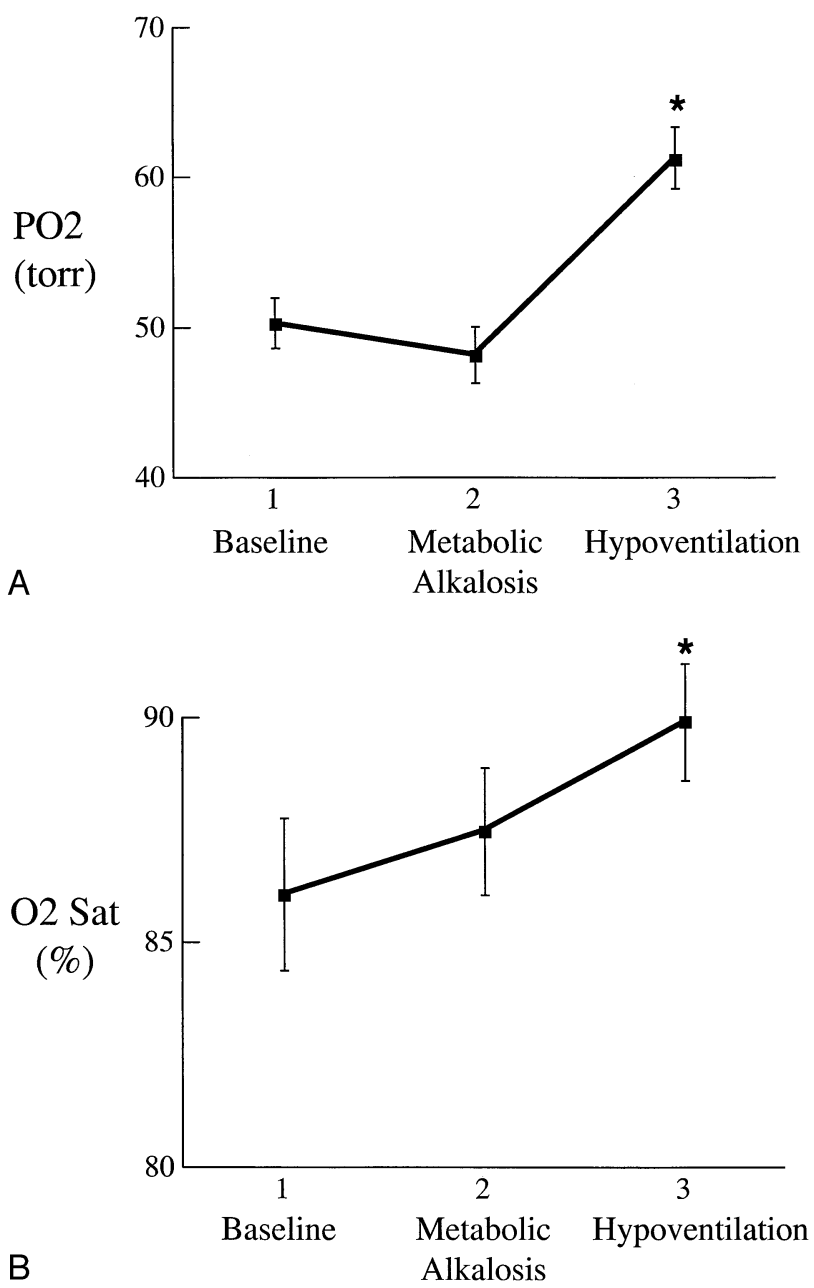

Figure 1. A, Arterial $\mathrm{Po}_{2}$ after $\mathrm{BSCC}$. $\mathrm{B}$, Systemic oxygen saturation after BSCC. Values are mean \pm SEM. ${ }^{*} P<.05$ versus baseline and metabolic alkalosis (Times 1 and 2; ANOVA).

change significantly (Figure 2). Transpulmonary gradient (pulmonary artery minus atrial pressure) therefore increased (from $6 \pm 1$ to $8 \pm 1 \mathrm{~mm} \mathrm{Hg}, P<.05$; Figure 2). Mean blood pressure decreased slightly during hypoventilation (Table 2). Mean heart rate did not change during the study (Table 2).

\section{Cerebral Blood Flow Indicators}

Hypoventilation also resulted in a significant increase in cerebral blood flow velocity. Mean cerebral blood flow velocity was $37 \pm 3 \mathrm{~cm} / \mathrm{s}$ at baseline, rose somewhat after administration of bicarbonate, and increased to $55 \pm 5 \mathrm{~cm} / \mathrm{s}$ during hypoventilation (Figure 3). Arteriovenous oxygen saturation difference across the upper body was derived as the systemic minus the pulmonary artery (superior vena caval) oxygen saturation. Upper body arteriovenous oxygen saturation difference was $33 \% \pm 2 \%$ at baseline, fell 


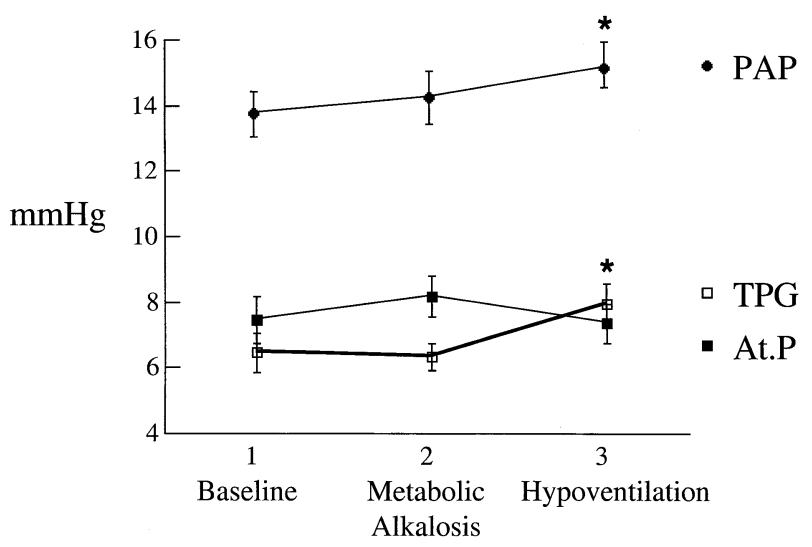

Figure 2. Hemodynamic values after BSCC. PAP, pulmonary artery pressure; $T P G$, transpulmonary gradient; $A$ t. $P$, atrial pressure. Values are mean \pm SEM. ${ }^{*} P<.05$ for PAP and TPG versus baseline and metabolic alkalosis (Times 1 and 2; ANOVA).

TABLE 2. Hemodynamic parameters

\begin{tabular}{|c|c|c|c|}
\hline & $\begin{array}{c}\text { Time 1, } \\
\text { baseline }\end{array}$ & $\begin{array}{c}\text { Time 2, } \\
\text { metabolic } \\
\text { alkalosis }\end{array}$ & $\begin{array}{c}\text { Time } 3, \\
\text { hypoventilation }\end{array}$ \\
\hline $\begin{array}{l}\text { Heart rate (beats/min) } \\
\text { Blood pressure }(\mathrm{mm} \mathrm{Hg})\end{array}$ & $134 \pm 3$ & $137 \pm 3$ & $137 \pm 4$ \\
\hline Mean & $70 \pm 3$ & $74 \pm 3$ & $65 \pm 2 \dagger$ \\
\hline Systolic & $96 \pm 3$ & $102 \pm 3^{*}$ & $92 \pm 4$ \\
\hline Diastolic & $56 \pm 2$ & $56 \pm 2$ & $50 \pm 2 \dagger$ \\
\hline
\end{tabular}

${ }^{*} P<0.05$ versus baseline and hypoventilation (Times 1 and 3; ANOVA). $\mathrm{\dagger} P<0.05$ versus baseline and metabolic alkalosis (Times 1 and 2; ANOVA).

slightly after administration of bicarbonate, and decreased to $23 \% \pm 1 \%$ during hypoventilation $(P<.05$; Figure 4$)$.

\section{Discussion}

This study shows that hypoventilation improves systemic oxygenation after BSCC. In our study patients, hypoventilation resulted in significant increases in both arterial $\mathrm{PO}_{2}$ and systemic oxygen saturation. These increases occurred despite small increases in pulmonary artery pressure and transpulmonary gradient. These results complement those of our previous study on the effects of hyperventilation in patients following BSCC. ${ }^{9}$ In that study, hyperventilation produced the opposite effect, a significant decrease in systemic oxygenation. ${ }^{9}$

Although many patients have adequate oxygenation after BSCC, some have clinically important hypoxemia. Several groups have examined risk factors for early postoperative hypoxemia after BSCC. Bradley and colleagues ${ }^{3}$ found that among patients younger than 6.5 months of age at BSCC, those under 4 months of age had lower oxygen saturations for the first 48 hours after surgery. Slavik and colleagues ${ }^{5}$ observed oxygen saturations below $70 \%$ for the first day

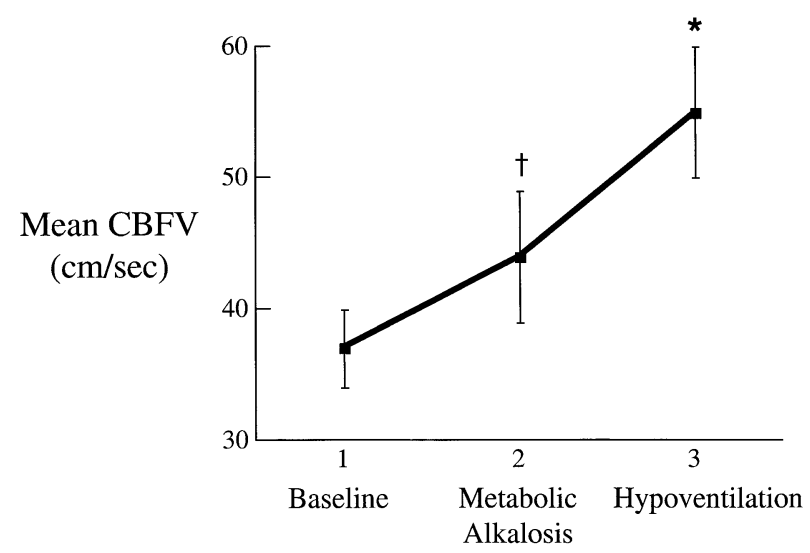

Figure 3. Mean cerebral blood flow velocity after BSCC. Values are mean \pm SEM. $+P<.05$ versus baseline (Time 1; ANOVA); * $P$ $<.05$ versus baseline and metabolic alkalosis (Times 1 and 2; ANOVA).

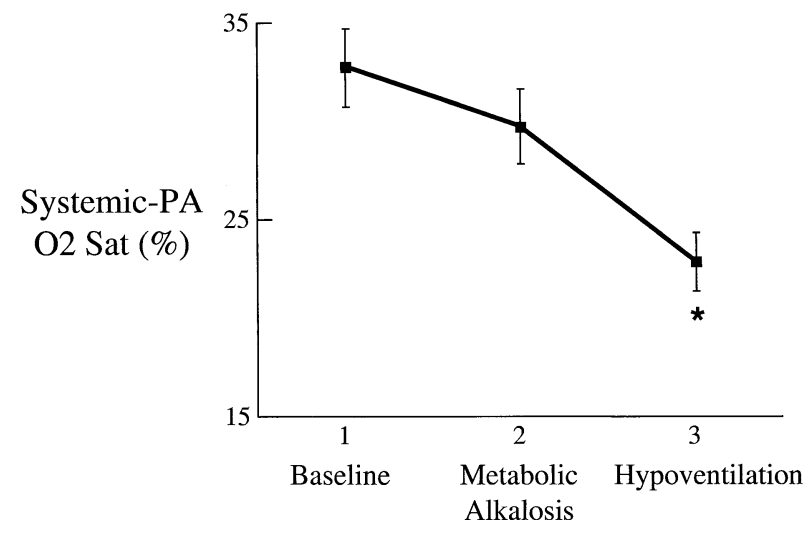

Figure 4. Upper body arteriovenous (systemic minus pulmonary artery) oxygen saturation difference after BSCC. Values are mean \pm SEM. ${ }^{*} \boldsymbol{P}<.05$ versus baseline and metabolic alkalosis (Times 1 and 2; ANOVA).

after surgery in 3 of 4 patients under 2 months of age at BSCC. Both groups noted resolution of hypoxemia by the time of hospital discharge. ${ }^{3,5}$ Aeba and coworkers ${ }^{6}$ found that age less than 8 months and greater preoperative ventricular volume load were associated with a lower oxygen saturation in the first 48 hours after BSCC. Bridges and associates ${ }^{1}$ found that higher preoperative pulmonary artery pressure and pulmonary vascular resistance were associated with a postoperative oxygen saturation below $75 \%$. Postoperative hypoxemia can contribute to patient mortality following BSCC, particularly in patients below roughly 6 months of age. ${ }^{3,4,7}$ Thus hypoxemia can be a clinically significant issue early after BSCC.

One approach to hypoxemia after BSCC is the addition of an accessory source of pulmonary blood flow, such as a 
systemic-to-pulmonary artery shunt. ${ }^{1,2,4}$ Patients with a BSCC and an accessory source of pulmonary flow ("pulsatile bidirectional Glenn") have higher systemic oxygen saturations than those without accessory flow. ${ }^{15,16}$ However, they also have higher pressure in the superior vena cava ${ }^{15,16}$ and increased incidences of pleural effusion and chylothorax. ${ }^{15-17}$ They also may have higher mortality in both the short term ${ }^{16}$ and long term. ${ }^{17}$ There is thus a need for alternative approaches in patients with hypoxemia early after BSCC. Because hypoxemia resolves over a period of days in many such patients, ${ }^{3,5}$ ventilatory strategies such as hypoventilation may be particularly useful.

An explanation for the increased oxygen levels seen during hypoventilation in this study involves an associated rise in cerebral blood flow. Hypoventilation produces hypercarbia (Table 1). Elevation of $\mathrm{PCO}_{2}$ to the levels seen in this study is known to decrease cerebral vascular resistance and increase cerebral blood flow. ${ }^{10}$ After BSCC, increased cerebral flow would result in more flow through the superior vena cava, more pulmonary blood flow, and higher systemic oxygen levels. This explanation is supported by the changes observed in 2 indicators of cerebral blood flow: blood flow velocity in the middle cerebral artery and arteriovenous oxygen saturation difference across the upper body. Both indicated that cerebral flow increased during hypoventilation.

Several considerations suggest that middle cerebral artery flow velocity can serve as an indicator of cerebral blood flow. Changes in mean flow velocity indicate changes in flow through a vessel as long as the vessel diameter remains constant. In an angiographic study of patients ranging in age from 0 to 70 years, the diameter of the large cerebral arteries, such as the middle cerebral artery, remained constant as arterial $\mathrm{PCO}_{2}$ increased from 40 to $57 \mathrm{~mm} \mathrm{Hg} .{ }^{18}$ During hypothermic cardiopulmonary bypass in children, the diameter of the middle cerebral artery has also been shown to remain constant over a wide range of temperature, blood pressure, and pump flow. ${ }^{19}$ Furthermore, changes in middle cerebral artery flow velocity have been found to correlate with changes in cerebral flow, when measured by internal carotid artery flow volume, ${ }^{20}$ the Kety-Schmidt method, ${ }^{21}$ and Xenon washout techniques. ${ }^{22-24}$ In particular, correlation with Xenon washout has been found during hypercarbia, ${ }^{22}$ as well as during and after hypothermic cardiopulmonary bypass using both $\mathrm{pH}$-stat and alpha-stat acid-base management. ${ }^{24}$ Thus cerebral flow velocity may serve as an indicator of cerebral blood flow under a variety of conditions.

In the current study, flow velocity in the middle cerebral artery (12 patients), or the anterior cerebral artery (2 patients), was measured by transcranial Doppler sonography. Mean flow velocity increased significantly during hypoventilation (Figure 3). The flow velocities measured were sim- ilar to those in a previous study of children after cardiopulmonary bypass. ${ }^{25}$ The flow velocity changes were also similar (in both size and direction) to those seen during hypoventilation in normal subjects, ${ }^{26}$ as well as in children after cardiopulmonary bypass. ${ }^{11}$ Thus our cerebral flow velocity findings are in line with those of previous studies and suggest that cerebral blood flow increased during hypoventilation in our patients.

The second indicator of cerebral blood flow that we examined was the arteriovenous oxygen saturation difference across the upper body. By the Fick principle, in the face of constant oxygen consumption, an increase in blood flow should produce a decrease in arteriovenous oxygen saturation difference. During hypoventilation in our patients, this difference decreased significantly (Figure 4). This finding is consistent with an increase in cerebral (and therefore upper body) blood flow during hypoventilation.

Other factors may have also contributed to increased oxygen levels during hypoventilation. Decreased mean airway pressure during hypoventilation (Table 1) could have lowered pulmonary vascular resistance, thereby increasing pulmonary blood flow and systemic oxygenation. Although the increases in mean pulmonary artery pressure and transpulmonary gradient observed during hypoventilation (Figure 2) suggested increased pulmonary flow, they were not consistent with a primary role of decreased pulmonary resistance. Nonetheless, the effects of decreased airway pressure may have added to the effect of hypercarbia on cerebral blood flow. It is also possible that cardiac output increased during hypoventilation, for at least 2 reasons. First, decreased mean airway pressure and intrathoracic pressure could have increased venous return. Second, hypercarbia is known to cause systemic vasodilation and therefore decreased ventricular afterload. ${ }^{27}$ The decreases in diastolic and mean systemic blood pressure observed during hypoventilation (Table 2) are consistent with vasodilation. Increased cardiac output could have increased not only upper body and pulmonary blood flow but also lower body flow and oxygen saturation in the inferior vena cava. Increased inferior vena cava oxygen saturation will increase systemic oxygenation in patients with right-to-left intracardiac shunting, as occurs after BSCC. We did not measure either cardiac output or inferior vena cava oxygen saturation, which are limitations of the study.

In the current study, we wished to avoid the potential negative effects of acidosis during hypoventilation. Decreased $\mathrm{pH}$ is known to increase pulmonary resistance in both children and adults after cardiopulmonary bypass. ${ }^{28,29}$ In a patient following BSCC, an increase in pulmonary resistance might decrease pulmonary blood flow and systemic oxygen levels and increase pressure in the superior vena cava. Beyond its effect on pulmonary resistance, acidosis has a number of other physiologic effects that would 
also be undesirable in an infant early after cardiac surgery. These include hyperkalemia and decreased myocardial $\beta$-adrenergic receptor affinity. ${ }^{30,31}$ A strategy of administering sodium bicarbonate before hypoventilation (pH-buffered hypoventilation) was successful in producing hypercarbia without an important fall in $\mathrm{pH}$ (Table 1). This strategy has been previously used to produce hypercarbia in a study of pulmonary resistance in infants after cardiac surgery. ${ }^{8,28}$ Hypercarbia may also have positive effects in patients other than those undergoing BSCC. For example, hypercarbia produced by adding carbon dioxide to the inspired gas mixture ("inspired $\mathrm{CO}_{2}$ ") has been shown to improve systemic oxygen delivery in neonates with hypoplastic left heart syndrome, both before and after the Norwood procedure. ${ }^{32,33} \mathrm{By}$ avoiding the potential negative effects of decreased $\mathrm{pH}$, a strategy of bicarbonate plus hypoventilation ( $\mathrm{pH}$-buffered hypoventilation) may be a clinically useful approach in a variety of patients.

During metabolic alkalosis (Time 2), we observed changes consistent with increased cerebral and pulmonary blood flow, namely increases in cerebral blood flow velocity and systemic oxygen saturation, and a decrease in arteriovenous oxygen saturation difference across the upper body (Figures $1 B, 3,4$ ). All of these changes were numerically small, with only the cerebral flow velocity achieving statistical significance. A small decrease in $\mathrm{Po}_{2}$ (also not significant, Figure $1 A$ ) may have been due to alkalosis causing a leftward shift of the oxyhemoglobin dissociation curve, resulting in a lower $\mathrm{PO}_{2}$ for any given oxygen saturation. During metabolic alkalosis, increased $\mathrm{pH}$ may have lowered pulmonary resistance, or the small increase in $\mathrm{PCO}_{2}(\mathrm{Table}$ 1) may have lowered cerebral resistance. However, the small magnitude of the changes prevents any firm conclusions on the effects of metabolic alkalosis in patients after BSCC.

The design of the current study has several strengths. It was prospectively conducted, and each patient served as his or her own control. Many respiratory and cardiac variables were controlled, so as to isolate the effects of metabolic alkalosis and hypoventilation. The study patients were sedated, paralyzed, and maintained at normothermia, to eliminate spontaneous respiration and to minimize responses to stimulation and changes in oxygen consumption. No patient had significant bleeding or received blood transfusion during the study, and inotropes were infused at constant rates. $\mathrm{FIO}_{2}$ was set at $100 \%$ to overcome effects of ventilationperfusion mismatch. Finally, the BSCC provided the only source of pulmonary flow in all study patients. This isolated the effects of hypoventilation on the BSCC without any confounding effects of additional sources of pulmonary flow.

This study also has several limitations. As noted above, in these infants early after cardiac surgery, cardiac output and cerebral and pulmonary blood flow were not directly measured. The effects of hypoventilation were examined over a short time period; the duration of the hypoventilation-induced increase in oxygenation remains unknown. The study design did not allow us to eliminate the possibility that some of the changes observed at Time 3 were due to the effects of sodium bicarbonate at a later time. Finally, some of the patients in this study underwent operations utilizing aortic crossclamping (in 11/15) or deep hypothermic circulatory arrest (in 8/15). Although these are widely used techniques for BSCC, in particular the hemi-Fontan procedure, ${ }^{3,12-14}$ our results may not necessarily extend to patients operated under different conditions.

The results of this study extend those of our previous study on the effects of hyperventilation in patients following BSCC. ${ }^{9}$ In that study, hyperventilation produced significant decreases in arterial $\mathrm{PO}_{2}$, systemic oxygen saturation, and mean cerebral blood flow velocity. The hypocarbia produced by hyperventilation likely causes increased cerebral vascular resistance, decreased cerebral and pulmonary blood flow, and decreased systemic oxygenation. ${ }^{9}$ The results of that study suggested that hyperventilation should be avoided in patients following BSCC.

The current study demonstrates that hypoventilation improves systemic oxygenation after BSCC. Although many patients have adequate oxygenation after BSCC, some will have clinically important hypoxemia. ${ }^{1,3-5}$ This can be a particular problem in young patients, early after surgery. ${ }^{3-5}$ Because the BSCC places the cerebral and pulmonary vascular beds in series, it is possible that decreased cerebral blood flow might contribute to postoperative hypoxemia in some patients. This possibility requires further study. The current study utilized an approach of sodium bicarbonate administration before hypoventilation to produce hypercarbia without accompanying acidosis (pH-buffered hypoventilation). This may be a useful clinical strategy in patients who are hypoxemic in the early postoperative period following BSCC.

\section{References}

1. Bridges ND, Jonas RA, Mayer JE, Flanagan MF, Keane JF, Castaneda AR. Bidirectional cavopulmonary anastomosis as interim palliation for high-risk Fontan candidates. Circulation. 1990;82(Suppl IV):IV170-6.

2. Pridjian AK, Mendelsohn AM, Lupinetti FM, et al. Usefulness of the bidirectional Glenn procedure as staged reconstruction for the functional single ventricle. Am J Cardiol. 1993;71:959-62.

3. Bradley SM, Mosca RS, Hennein HA, Crowley DC, Kulik TJ, Bove EL. Bidirectional superior cavopulmonary connection in young infants. Circulation. 1996;94(Suppl II):II5-11.

4. Reddy VM, Liddicoat JR, Hanley FL. Primary bidirectional superior cavopulmonary shunt in infants between 1 and 4 months of age. Ann Thorac Surg. 1995;59:1120-6.

5. Slavik Z, Lamb RK, Webber SA, et al. Bidirectional superior cavopulmonary anastomosis: how young is too young? Heart. 1996;75:7882

6. Aeba R, Katogi T, Kashima I, Omoto T, Kawada S, Omae K. Factors influencing arterial oxygenation early after bidirectional cavopulmo- 
nary shunt without additional sources of pulmonary blood flow. $J$ Thorac Cardiovasc Surg. 2000;120:589-95.

7. Reddy VM, McElhinney DB, Moore P, Haas GS, Hanley FL. Outcomes after bidirectional cavopulmonary shunt in infants less than 6 months old. J Am Coll Cardiol. 1997;29:1365-70.

8. Castaneda AR, Jonas RA, Mayer JE, Hanley FL. Perioperative care. In:. Cardiac surgery of the neonate and infant. Philadelphia: W.B. Saunders; 1994. p. 76-82.

9. Bradley SM, Simsic JM, Mulvihill DM. Hyperventilation impairs oxygenation after bidirectional superior cavopulmonary connection. Circulation. 1998;98(Suppl II):II372-7.

10. Madden JA. The effect of carbon dioxide on cerebral arteries. Pharmac Ther. 1993;59:229-50.

11. Kawaguchi M, Ohsumi H, Ohnishi Y, Nakajima T, Kuro M. Cerebral vascular reactivity to carbon dioxide before and after cardiopulmonary bypass in children with congenital heart disease. J Thorac Cardiovasc Surg. 1993;106:823-7.

12. Norwood WI, Jacobs ML. Fontan's procedure in two stages. Am J Surg. 1993; 166:548-51.

13. Douglas WI, Goldberg CS, Mosca RS, Law IH, Bove EL. HemiFontan procedure for hypoplastic left heart syndrome: outcome and suitability for Fontan. Ann Thorac Surg. 1999;68:1361-8.

14. Spray TL. Fenestrated Fontan for hypoplastic left heart syndrome. Operative Techniques in Cardiac \& Thoracic Surgery. 1997;2:239-52.

15. Frommelt MA, Frommelt PC, Berger S, et al. Does an additional source of blood flow alter outcome after a bidirectional cavopulmonary shunt? Circulation. 1995;92(Suppl II):II240-4.

16. McElhinney DB, Marianeschi SM, Reddy VM. Additional pulmonary blood flow with the bidirectional Glenn anastomosis: does it make a difference? Ann Thorac Surg. 1998;66:668-72.

17. Mainwaring RD, Lamberti JJ, Uzark K, Spicer RL, Cocalis MW, Moore JW. Effect of accessory pulmonary blood flow on survival after the bidirectional Glenn procedure. Circulation. 1999;100(Suppl II): II151-6.

18. Huber P, Handa J. Effect of contrast material, hypercapnia, hyperventilation, hypertonic glucose and papaverine on the diameter of the cerebral arteries; angiographic determination in man. Investigative Radiology. 1967;2:17-32.

19. van der Linden J, Priddy R, Ekroth R, et al. Cerebral perfusion and metabolism during profound hypothermia in children; a study of middle cerebral artery ultrasonic variables and cerebral extraction of oxygen. J Thorac Cardiovasc Surg. 1991;102:103-14.

20. Lindegaard K, Lundar T, Wiberg J, Sjoberg D, Aaslid R, Nornes H. Variations in middle cerebral artery blood flow investigated with noninvasive transcranial blood velocity measurements. Stroke. 1987; 18:1025-30.
21. Weyland A, Stephan H, Grune F, Weyland W, Sonntag H. Effect of ketanserin on global cerebral blood flow and middle cerebral artery flow velocity. Anesth Analg. 1995;80:64-70.

22. Bishop CCR, Powell S, Rutt D, Browse NL. Transcranial Doppler measurement of middle cerebral artery blood flow velocity: a validation study. Stroke. 1986;17:913-5.

23. Larsen FS, Olsen KS, Hansen BA, Paulson OB, Knudsen GM. Transcranial Doppler is valid for determination of the lower limit of cerebral blood flow autoregulation. Stroke. 1994;25:1985-8.

24. Trivedi UH, Patel RL, Turtle MRJ, Venn GE, Chambers DJ. Relative changes in cerebral blood flow during cardiac operations using xenon133 clearance versus transcranial Doppler sonography. Ann Thorac Surg. 1997;63:167-74.

25. Jonassen AE, Quaegebeur JM, Young WL. Cerebral blood flow velocity in pediatric patients is reduced after cardiopulmonary bypass with profound hypothermia. J Thorac Cardiovasc Surg. 1995;110: 934-43.

26. Markwalder T, Grolimund P, Seiler RW, Roth F, Aaslid R. Dependency of blood flow velocity in the middle cerebral artery on end-tidal carbon dioxide partial pressure-a transcranial ultrasound Doppler study. J Cereb Blood Flow Metab. 1984;4:368-72.

27. Moody EJ, Simon BA, Johns RA. Therapeutic gases: oxygen, carbon dioxide, nitric oxide, and helium. In: Hardman JG, Limbird LE, editors. Goodman \& Gilman's the pharmacological basis of therapeutics. New York: McGraw-Hill; 2001. p. 393-4.

28. Chang AC, Zucker HA, Hickey PR, Wessel DL. Pulmonary vascular resistance in infants after cardiac surgery: role of carbon dioxide and hydrogen ion. Crit Care Med. 1995;23:568-74.

29. Fullerton DA, Kirson LE, St. Cyr JA, Kinnard T, Whitman GJR. Influence of hydrogen ion concentration versus carbon dioxide tension on pulmonary vascular resistance after cardiac operation. $J$ Thorac Cardiovasc Surg. 1993;106:528-36.

30. Benumof JL. Respiratory physiology and respiratory function during anesthesia. In: Miller RD, editor. Anesthesia. New York: Churchill Livingstone; 1990. p. 544-5.

31. Modest VE, Butterworth JF IV. Effect of $\mathrm{pH}$ and lidocaine on $\beta$-adrenergic receptor binding. Chest. 1995;108:1373-9.

32. Tabbutt S, Ramamoorthy C, Montenegro LM, et al. Impact of inspired gas mixtures on preoperative infants with hypoplastic left heart syndrome during controlled ventilation. Circulation. 2001;104(Suppl I): I159-64.

33. Bradley SM, Simsic JM, Atz AM. Hemodynamic effects of inspired carbon dioxide after the Norwood procedure. Ann Thorac Surg. 2001; 72:2088-94. 